\title{
Correction
}

\section{Correction: Bonner et al., Grafted Neural Progenitors Integrate and Restore Synaptic Activity across the Injured Spinal Cord}

In the article "Grafted Neural Progenitors Integrate and Restore Synaptic Activity across the Injured Spinal Cord” by Joseph F. Bonner, Theresa M. Connors, William F. Silverman, David P. Kowalski, Michel A. Lemay, and Itzhak Fischer, which appeared on pages 4675-4686 of the March 23, 2011 issue, the Materials and Methods section under the heading of Surgical procedures stated "Bupranorphin (J. A. Webster) was used for pain relief every $12 \mathrm{~h}$ for $3 \mathrm{~d}$ and then as needed for the remainder of the study". This statement should be replaced by "Acetaminophen $(32 \mathrm{mg} / \mathrm{kg}$, oral suspension) was used for pain relief twice daily as needed for the remainder of the study". This correction does not affect data interpretation or the conclusions of the paper.

DOI: 10.1523/JNEUROSCI.1003-13.2013 